\title{
Cancer shoulder pain treated with a neurolytic erector spinae plane block
}

\author{
Patricia Papa, MD • Mariano Antunez-Maciel, MD • Juan-Francisco Asenjo, MD, \\ FRCPC
}

Received: 18 February 2020/Revised: 11 March 2020/Accepted: 12 March 2020/Published online: 25 March 2020

(C) Canadian Anesthesiologists' Society 2020

\section{To the Editor,}

Cancer pain is experienced by over $80 \%$ of patients with advanced malignancies, and pharmacotherapy is usually a first line treatment approach. Nevertheless, $15-20 \%$ of patients report severe pain in spite of optimal medical management with strong opioids and co-adjuvants. Often, interventional approaches are required because of low response to opioid drugs or intolerable adverse effects. The report in 2016 by Forero et al. ${ }^{1}$ outlining the treatment of severe neuropathic pain using an erector spinae plane (ESP) block established it as a successful approach for analgesia in several painful conditions including acute/ chronic shoulder pain.

This report present the case of a 56-yr-old man (who consented to this report) diagnosed with squamous cell carcinoma of the left lung with extensive local and regional (supraclavicular) spread that progressed despite several lines of treatment. His main problem was severe left supraclavicular pain refractory to opioids, co-analgesics (methadone $40 \mathrm{mg} \cdot \mathrm{day}^{-1}$, pregabalin $150 \mathrm{mg} \cdot \mathrm{day}^{-1}$ ), and rescue medication with morphine sc $40 \mathrm{mg} \cdot \mathrm{day}^{-1}$. He experienced mixed nociceptive and neuropathic pain (questionnaire DN4, 7/10) that radiated from the

\footnotetext{
P. Papa, MD

Pain Medicine and Palliative Care, Sanatorio Medica Uruguaya, Montevideo, Uruguay
}

M. Antunez-Maciel, MD

Department of Anesthesia and Pain Medicine, Sanatorio Medica

Uruguaya, Montevideo, Uruguay

J.-F. Asenjo, MD, FRCPC ( $\varangle)$.

Department of Anesthesia, The Montreal General Hospital,

Montreal, QC, Canada

e-mail: jfasenjog@gmail.com supraclavicular region to the shoulder and proximal upper arm, as well as across the front and back of the upper left chest area. He reported dysesthesia and loss of strength in the left upper limb. His pain was disabling, preventing sleep and rest, and requiring him to remain seated with his head in a semi-flexed erect posture to avoid a triggering pain crisis.

A diagnostic ultrasound-guided ESP block was proposed, explained and planned. After written consent was obtained, a left ESP block was performed under aseptic conditions in the seated position at the T2 level using a mixture of $15 \mathrm{~mL} 0.25 \%$ bupivacaine and $15 \mathrm{~mL}$ $1 \%$ lidocaine. After $15 \mathrm{~min}$, the patient reported a decrease in visual analogue score (VAS) for pain from $9 / 10$ to $3 / 10$. He was able to sleep lying on his back, but after $24 \mathrm{hr}$ he reported the return of pain albeit of a lower intensity than before. Given this initial favourable response, a neurolytic ESP block with $8 \%$ aqueous solution of phenol was planned. The neurolytic ESP block was performed at the same location. The patient was monitored as he was injected with $15 \mathrm{~mL}$ of $8 \%$ phenol aqueous solution in fractional doses (5 mL every five minutes) without local anesthetics. At 30 min post-injection, he reported no pain at rest (0/10 VAS) and only mild discomfort while moving his arm (3/10 VAS). The patient reported adequate pain control for three weeks (methadone reduced to $30 \mathrm{mg} /$ day) and lower static (0/10 VAS) and dynamic (3/10 VAS) pain scores. No rescue analgesia with morphine was required. The intense pain relief lasted for approximately four weeks. After that, the VAS slowly increased, though never returned to the pre-block intensity level. Methadone was re-adjusted to cope with the progressive nociceptive mass.

Ultrasound-guided chemical neurolysis with phenol in fascial planes has already been successfully used in other refractory cancer pain cases. ${ }^{2}$ This neurolytic procedure 
was selected on the basis of the report of radio-opaque contrast dispersion from $\mathrm{T} 2$ toward the anterior planes and nearby foramina, as well as the positive outcome from the initial diagnostic block in this patient. As this communication was prepared, a case was reported using neurolytics in the ESP. ${ }^{3}$ Nevertheless, in that case the treatment was applied to the classic ESP location in the chest. In our patient, the neurolytic ESP block was favoured over a cervical epidural or a brachial plexus, because of cost considerations, simpler performance, and easier ambulatory management. Schwartzmann et $a l^{4}$ reported an in vivo study in patients documenting the spread of the ESP block using magnetic resonance imaging after injection of gadolinium. In only one of six individuals studied was there significant epidural distribution of gadolinium seen (and with twice the volume injected compared with the case presented here). Therefore, with a careful and slow injection, we did not expect any significant risk of epidural spread (had this occurred, it would likely have manifested as mild hypoesthesia in areas outside the targeted pain source). Importantly, a small extension of the neurolytic solution to the epidural space should not deter indication for this ESP block as epidural phenol injection (in experts hands) is a well-established technique for relieving cancer pain. ${ }^{5}$

We believe our case introduces the possibility of treating upper extremity cancer pain with this new approach, avoiding perhaps the motor blockade induced by a brachial plexus block. The procedure clearly improved the analgesia and quality of life for the patient.
Conflicts of interest None.

Funding statement None.

Editorial responsibility This submission was handled by Dr. Hilary P. Grocott, Editor-in-Chief, Canadian Journal of Anesthesia.

\section{References}

1. Forero M, Adhikary SD, Lopez H, Tsui C, Chin KJ. The erector spinae plane block: a novel analgesic technique in thoracic neuropathic pain. Reg Anesth Pain Med 2016; 41: 621-7.

2. Restrepo-Garces CE, Asenjo JF, Gomez CM, et al. Subcostal transversus abdominis plane phenol injection for abdominal wall cancer pain. Pain Pract 2014; 14: 278-82.

3. Hernández-Porras BC, Rocha A, Juárez AM. Phenol spread in erector spinae plane block for cancer pain. Reg Anesth Pain Med 2019. DOI: https://doi.org/10.1136/rapm-2019-100509.

4. Schwartzmann A, Peng P, Antunez Maciel M, Alcarraz $P$, Gonzalez X, Forero M. A magnetic resonance imaging study of local anesthetic spread in patients receiving an erector spinae plane block. Can J Anesth 2020. DOI: https://doi.org/10.1007/s12630020-01613-8.

5. de Pinto $M$, Naidu RK. Peripheral and neuraxial chemical neurolysis for the management of intractable lower extremity pain in a patient with terminal cancer. Pain Physician 2015; 18: E651-6.

Publisher's Note Springer Nature remains neutral with regard to jurisdictional claims in published maps and institutional affiliations. 